\title{
Impression cytology of the ocular surface
}

\author{
R Singh, A Joseph, T Umapathy, N L Tint, H S Dua
}

Br J Ophthalmol 2005;89:1655-1659. doi: 10.1136/bjo.2005.073916

Impression cytology refers to the application of a cellulose acetate filter to the ocular surface to remove the superficial layers of the ocular surface epithelium. These cells can then be subjected to histological, immunohistological, or molecular analysis. Proper technique is essential as the number of cells sampled can vary considerably. Generally two to three layers of cells are removed in one application but deeper cells can be accessed by repeat application over the same site. Applications for impression cytology include diagnosing a wide range of ocular surface disorders, documenting sequential changes in the conjunctival and corneal surface over time, staging conjunctival squamous metaplasia, and monitoring effects of treatment. It is also a useful investigational tool for analysing ocular surface disease with immunostaining and DNA analysis. It is non-invasive, relatively easy to perform, and yields reliable information about the area sampled with minimal discomfort to the patient. Major ophthalmic centres should develop and introduce this technique into routine clinical practice. This is best achieved with a team approach including the ophthalmologist, pathologist, microbiologist, and the immunologist.

\begin{abstract}
See end of article for authors' affiliations

Correspondence to: Harminder S Dua, Division of Ophthalmology, B Floor, Eye ENT Centre, University Hospital, Queens Medical Centre, Nottingham NG7 2UH, UK; harminder.dua@ nottingham.ac.uk
\end{abstract}

Accepted for publication 28 July 2005
1 mpression cytology refers to the application of cellulose acetate filter to the ocular surface to remove the superficial layers of the ocular surface epithelium. The cells thus removed can be subjected to histological, immunohistological, or molecular analysis. Egbert et al first described this minimally invasive method of studying conjunctival goblet cells in $1977 .{ }^{1}$ Since then the technique has been used to evaluate several ocular surface disorders and modifications to the original technique have been introduced. It is non-invasive, easy to perform, and yields reliable information about the area sampled with minimal discomfort to the patient. This makes it a valuable tool in the understanding of ocular surface disorders. Applications of impression cytology include the aetiological diagnosis of various ocular surface disorders, documenting sequential changes in the conjunctival and corneal surface over time, monitoring effects of treatment and staging conjunctival squamous metaplasia, and as an investigational tool for analysing ocular surface disease with immunostaining and DNA analysis. $^{2}$

\section{IMPRESSION CYTOLOGY TECHNIQUE}

Egbert et al used Millipore filters to collect conjunctival specimens, which were then air dried and stained with periodic acid Schiff (PAS) and haematoxylin. ${ }^{1}$ Tseng modified the method of collection of specimens and stained them with a combination of PAS and Papanicolaou stains. ${ }^{2}$ Maskin and Bodé have described a technique with which conjunctival epithelial cells acquired by impression cytology can be studied by electron microscopy. ${ }^{3}$ Pure nitrocellulose membranes and Biopore membrane devices have been used to enable immunocytochemical staining. ${ }^{4}$

\section{SPECIMEN COLLECTION}

The type of filter paper used and the technique of cell collection depend on the purpose for which the specimen is collected. The size of the filter paper pores affects the consistency of epithelial cells collected and the resolution of cell detail. Larger pore sizes collect cells better, but the cell detail is less well preserved. Treatment of the filter paper with surfactant also reduces cell pick up. Most authors use surfactant free filter paper of a pore size between $0.22 \mu \mathrm{m}$ and $0.44 \mu \mathrm{m}$. $^{6}$

Tseng's modified method of specimen collection uses cellulose acetate filter paper from Millipore, which is trimmed into a $5 \mathrm{~mm}$ strip with one square end and one tapering end. The asymmetrical shape with a pointed tip facilitates grabbing and transferring the paper to the desired area with blunt smooth edged forceps. ${ }^{2}$ We use a $13 \mathrm{~mm}$ diameter Millipore paper divided in two " $\mathrm{D}$ "'-shaped halves (fig 1). The end of the paper to be applied to the nasal side is clipped for orientation. One drop of local anaesthetic is instilled into the eye and excessive tear fluid and medication are wiped away. The paper is applied on the conjunctiva or cornea or both together, straddling the limbus. The area to be sampled depends on the underlying pathology. The filter paper is smoothed onto the ocular surface by applying gentle pressure with a Goldmann tonometer headpiece held between finger and thumb. The smooth flat surface of the headpiece allows uniform pressure to be applied over the surface area of the paper. The paper is allowed to remain in contact with the eye for approximately 5-10 seconds and then peeled off with a forceps. During the period of contact it is important that the lids are held away from the paper and it is not allowed to be wetted by tear fluid that may at times appear as a result of stimulation of lacrimation. If the paper gets

Abbreviations: OSSN, ocular surface squamous neoplasia; PAS, periodic acid Schiff; RT PCR, reverse transcriptase polymerase chain reaction; TDC, total dye content 


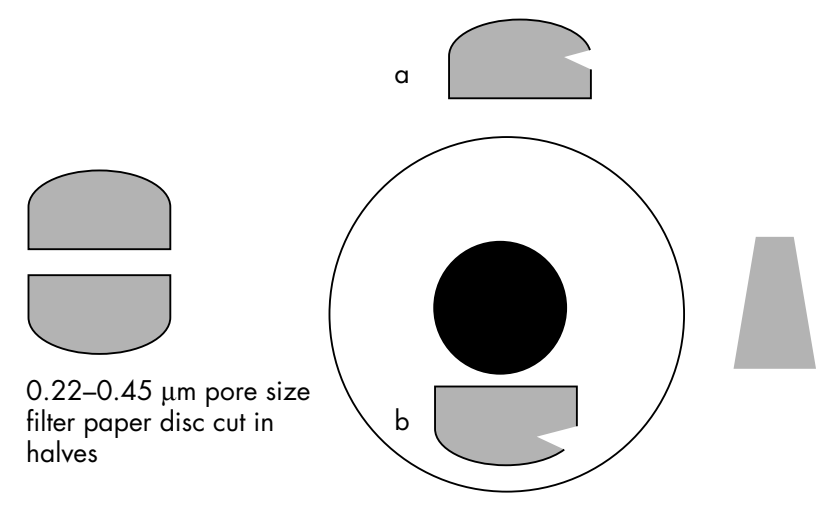

Dry area to be sampled. Apply paper with a notch to mark side. Straight edge towards limbus (a) or corneal centre (b). Press firmly with Goldmann tonometer head. Peel off paper with forceps and place in appropriate fixative solution

Figure 1 Schematic representation of impression cytology procedure as followed by the authors, showing cut filter paper disc into halves (left) and application of resulting D-shaped segments (clipped for orientation) on bulbar conjunctiva and cornea using Goldmann tonometer head, to apply even pressure on filter paper (right).

unduly wet, the yield of cells will be poor. The paper is immediately transferred into a well of a 24 well plate containing fixative solution. It may be necessary to mark the back of the paper before applying it on to the ocular surface so that the surface to be stained later can be easily identified.

\section{SPECIMEN STAINING}

Papanicolaou or haematoxylin and PAS stains are the commonly used stains for routine histological staining of impression cytology specimens. The filter paper with the specimen is fixed for approximately 10 minutes in a solution containing glacial acetic acid, formaldehyde, and ethyl alcohol in a 1:1:20 volume ratio. ${ }^{2}$ A 24 well culture plate or a 24 well Teflon sample holder is used to hold the specimens during fixation and staining. The specimens are rehydrated in $70 \%$ ethyl alcohol and then placed successively in periodic acid Schiff reagent, sodium metasulfite, Gill's haematoxylin, and Scott's tap water substitute for 2 minutes each, rinsing in two changes of tap water in between each step. ${ }^{7}$ This is followed by dehydration in two changes of $95 \%$ ethyl alcohol, staining with modified orange $\mathrm{G}$ for 2 minutes, rinsing in 95\% ethyl alcohol for 3 minutes, and staining with modified eosin Y for 2 minutes, again rinsing in 95\% ethyl alcohol for 5-10 minutes, before dehydration in absolute alcohol for 5 minutes. Throughout the staining the cell side of the filter paper must be completely soaked with staining solution. For each destaining or rinsing, the holder is either dipped 10 times or suspended in a large jar with continuous magnetic stirring so that there is no need for constant monitoring. ${ }^{2}$ After the final destaining step, xylene is used to make the filter paper transparent. Before mounting, the filter paper is placed with the epithelial cells facing up. The completed slides are examined by light microscopy.

\section{PREPARATION OF STAINING SOLUTIONS}

Gill et al have described the detailed preparation of each solution. ${ }^{7}$ Gill's haematoxylin is prepared by combining $365 \mathrm{ml}$ of distilled water, $125 \mathrm{ml}$ of ethylene glycol, $1 \mathrm{~g}$ of anhydrous haematoxylin, $0.1 \mathrm{~g}$ of sodium iodate, $8.8 \mathrm{~g}$ of aluminium sulphate, and $10 \mathrm{ml}$ of glacial acetic acid. The chemicals are stirred for 1 hour on a magnetic mixer at room temperature. The final solution is filtered through Whatman
No 1 filter paper before using it for the first time. Scott's tap water substitute consists of $1 \mathrm{~g}$ sodium bicarbonate and $5 \mathrm{~g}$ magnesium sulfate, anhydrous or $10 \mathrm{~g}$ magnesium sulfate, crystalline in $500 \mathrm{ml}$ of tap water. The $\mathrm{pH}$ of this solution is 8.02 and plays a significant part in determining the blue colour of the nuclei. Modified orange $G$ is made of $10 \mathrm{ml}$ orange G, 10\% total dye content (TDC) aqueous solution combined with $490 \mathrm{ml}$ of $95 \%$ ethyl alcohol and $0.075 \mathrm{~g}$ phosphotungstic acid. Modified eosin Y consists of $350 \mathrm{ml}$ of $95 \%$ ethyl alcohol, $125 \mathrm{ml}$ absolute methyl alcohol, $10 \mathrm{ml}$ glacial acetic acid, $0.18 \mathrm{~g}$ light green SF yellowish, $5 \mathrm{ml} \mathrm{3 \%}$ TDC aqueous solution, $10 \mathrm{ml}$ eosin Y 20\% TDC aqueous solution, and $\mathrm{l} \mathrm{g}$ phosphotungstic acid.

\section{SPECIAL TECHNIQUES}

Special staining techniques have been devised for studying the specimens by electron microscopy ${ }^{3}$ and immunocytochemistry. ${ }^{45}$ For electron microscopy, the specimen on cellulose acetate paper is fixed in $4 \%$ phosphate buffered formaldehyde with $1 \%$ glutaraldehyde and ruthenium red dye, post fixed in buffered osmium fixative, dehydrated, and embedded in resin. ${ }^{3}$ Immunocytochemical staining of impression cytology specimens collected on conventional cellulose acetate membranes results in high levels of background staining. Use of xylene to chemically clear the cellulose acetate filter destroys the cell surface antigen. To overcome this problem Krenzer and Freddo developed a method of collecting the specimen on a pure nitrocellulose membrane which was then fixed with a spray fixative, transferred on to a poly-L-lysine coated glass slide, and dried. The slide was then placed in acetone for 1 hour with continuous agitation to dissolve the filter membrane, washed for 5 minutes in tap water, and subjected to cellulose digestion for 2 hours at $37^{\circ} \mathrm{C}$ to remove residual membrane material before proceeding to immunocytochemical staining. ${ }^{4}$ Thiel et al used mounted Biopore membranes (Millicell-CM $0.4 \mu \mathrm{m}$ PICM 012550, Millipore Corp, Bedford, MA, USA) for the immunopathological diagnosis of superficial viral infections. The Biopore membrane is fully transparent in the wet state and allows a detailed cytological examination by light and fluorescence transmission microscopy. ${ }^{5}$

\section{MICROSCOPY AND CLINICAL APPLICATIONS}

An impression cytology usually removes only 1-3 cell layers and does not yield the same information as a flat mount or cross section preparation of the ocular surface. It is therefore ideal for studying the surface epithelium rather than the basal epithelium or the basement membrane (fig 2A). However, using multiple impressions of the same area (in vivo or in vitro cadaver eye) we were able to demonstrate the morphology of the basal limbal epithelium. The limbal cells are smaller, more densely packed, and have a greater nucleus to cytoplasm ratio compared to adjacent corneal and conjunctival cells (fig 2B). Morphologically Egbert first used this method to determine the density of goblet cells in different areas of the conjunctiva. ${ }^{1}$ He found the greatest density of goblet cells in the nasal palpebral conjunctiva, with decreasing densities in the temporal and palpebral conjunctiva, bulbar conjunctiva near the fornices, and the bulbar conjunctiva near the limbus. His results were similar to those obtained by studies of whole mounts of conjunctiva. Adams studied the morphology of normal human conjunctival mucus using impression cytology and described granules, strands, and structureless patterns of mucus on different parts of the conjunctiva. ${ }^{8}$

Impression cytology has also been used in the evaluation of ocular surface diseases such as keratoconjunctivitis sicca, ${ }^{10}$ vitamin A deficiency, ${ }^{11}$ cicatricial pemphigoid, ${ }^{12}$ atopic disease, ${ }^{13}$ superior limbic keratoconjunctivitis and 

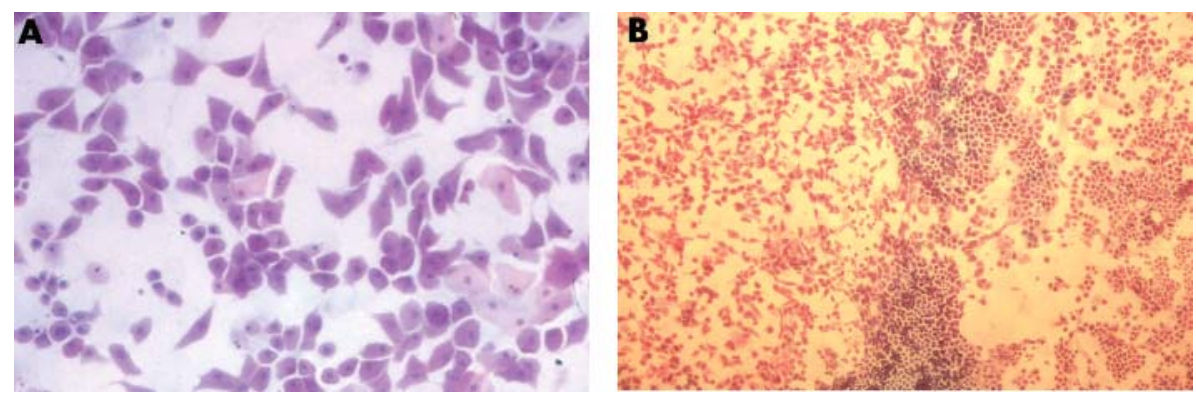

Figure 2 (A) Impression cytology of normal corneal surface showing corneal epithelial cells. Normal cells are flat with a prominent nucleus. The nuclear cytoplasmic ratio is low ( $\times 100$, periodic acid Schiff staining). (B) Impression cytology of normal transition zone from cornea to limbus $(\times 40$, periodic acid Schiff staining). The limbal epithelial cells are small, densely packed with a high nuclear cytoplasmic ratio. The limbal zone is clearly demarcated from the adjacent corneal epithelial cells.

mucopolysaccharidoses, ${ }^{3}$ vernal keratoconjunctivitis, ${ }^{14}$ and the effect on these of various therapies. Tseng classified conjunctival squamous metaplasia into six stages according to the presence or absence of goblet cells and goblet cell density, morphological changes of the nucleus, nucleuscytoplasm ratios, metachromatic changes of cytoplasmic colour, and emergence of keratinisation. ${ }^{2}$ Nelson graded conjunctival impression cytology specimens (grades 0-3, table 1) based on the appearance of the epithelial cells and the numbers of goblet cells. ${ }^{15}$ A specimen of small, round epithelial cells with large nuclei and more than 500 goblet cells $/ \mathrm{mm}^{2}$ was considered grade 0 , whereas another of large polygonal epithelial cells with small nuclei and less than 100 goblet cells $/ \mathrm{mm}^{2}$ was considered grade 3 . All specimens that were grade 2 or more were abnormal. The findings of grades 2 and 3 on the interpalpebral conjunctiva and grades 0 and 1 on the inferior palpebral ocular surface in the absence of inflammatory cells suggest a diagnosis of keratoconjunctivitis sicca, whereas grades 2 and 3 on both the bulbar and palpebral conjunctiva suggest an intrinsic ocular surface disease such as ocular cicatricial pemphigoid, StevensJohnson syndrome, or severe chemical burns. ${ }^{15}$ The presence of inflammatory cells suggests that the disease is active. Marner studied impression cytology specimens of conjunctival epithelial cells of patients with keratoconjunctivitis sicca and described a snake-like appearance of nuclear chromatin in clusters of abnormal cells from the upper bulbar conjunctiva (fig 3). ${ }^{9}$ Prabhasawat and Tseng used impression cytology to demonstrate normal conjunctival epithelial cells and goblet cells following ocular surface reconstruction by preserved amniotic membrane. ${ }^{16}$ Modifications of the impression cytology technique were made to study cytokeratin expression in bulbar conjunctiva by using pure nitrocellulose membranes and immunocytochemical staining. ${ }^{4}$ The conjunctiva was found to demonstrate a unique cytokeratin expression pattern containing cytokeratins characteristic of non-keratinised, stratified epithelia (K4 and K13) as well as others more typical of a simple differentiation pattern (K8 and K19), a glandular differentiation pattern (K7), or both. ${ }^{4}$ This technique was later used in the preoperative diagnosis of

\begin{tabular}{|c|c|}
\hline Grade & Features \\
\hline $\begin{array}{l}0 \\
1-2 \\
3\end{array}$ & $\begin{array}{l}>500 \text { goblet cells } / \mathrm{mm}^{2} \\
\text { Small, round epithelial cells with large nuclei } \\
100-500 \text { goblet cells } / \mathrm{mm}^{2} \\
<100 \text { goblet cells } / \mathrm{mm}^{2} \\
\text { Large, polygonal epithelial cells with small nuclei }\end{array}$ \\
\hline
\end{tabular}

seborrhoeic keratosis of the conjunctiva simulating a malignant melanoma. ${ }^{17}$ Thiel et al used a biopore membrane device to collect ocular surface specimens and apply immunopathological methods to diagnose superficial viral infections like herpes simplex virus, varicella zoster virus, and adenovirus. $^{5}$

More recently impression cytology has been used to demonstrate conjunctival metaplasia as a result of the use of topical antiglaucoma drugs. ${ }^{18}{ }^{19}$ Free radical production was found in patients on long term antiglaucoma treatment and contact lens wearers by investigations on impression cytology specimens. ${ }^{20}$ Immunohistochemistry on impression cytology specimens has been used to compare the efficacy of drugs and to determine the mechanism of action of topical agents in vernal conjunctivitis. ${ }^{21}$ Impression cytology has also helped in evaluation of ocular surface changes after excimer laser phototherapeutic keratectomy in patients with corneal dystrophies and other corneal pathology.22 It has enabled documentation of limbal cell deficiency in patients with

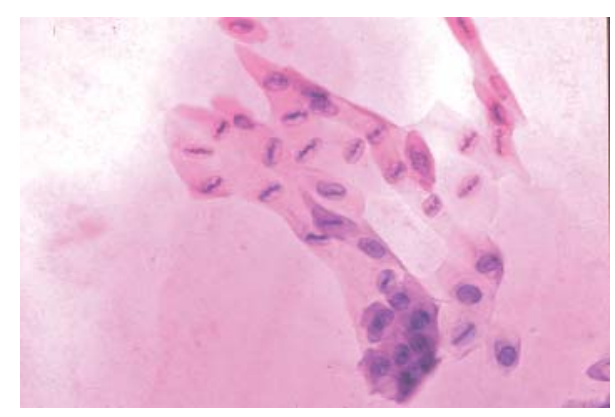

Figure 3 Impression cytology of the conjunctival surface showing snake-like chromatin in keratoconjunctivits sicca $(\times 100$, periodic acid Schiff staining).

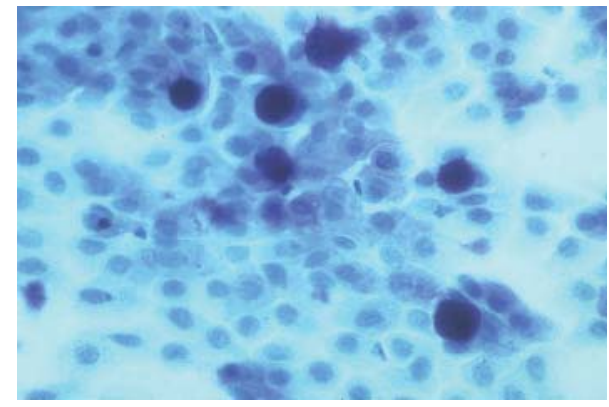

Figure 4 Impression cytology of the conjunctivalised corneal surface in limbal stem cell deficiency showing reddish pink goblet cells $(\times 100$, periodic acid Schiff staining). 


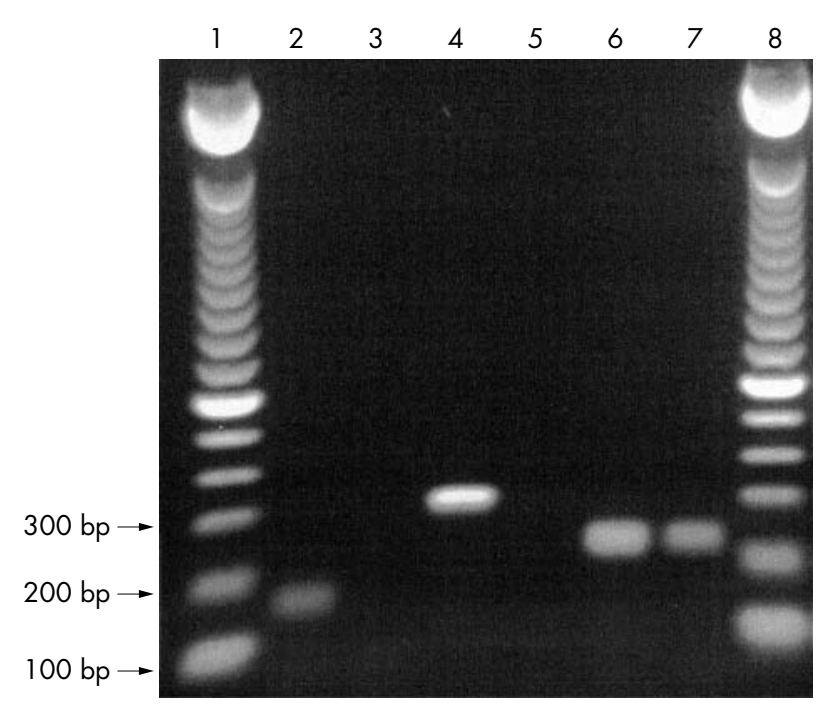

Figure 5 rtPCR image of cDNA extracted from cells obtained by impression cytology from cornea (lanes $3,5,7)$ and conjunctiva (lanes $2,4,6$ ). Primers for human $\beta$ defensins 1 and 2 were used. (Reproduced by courtesy of Masahel Al-Abed, Larry A Donoso Laboratory for Eye Research, Division of Ophthalmology, University of Nottingham).

ocular burns and other surface disorders by demonstrating the presence of goblet cells on the corneal surface (fig 4). ${ }^{23}$ Limbal stem cell deficiency has also been assessed using immunoperoxidase staining for cytokeratins: $\mathrm{K} 3$ for corneal, and $\mathrm{K} 19$ for conjunctival phenotype. The limitation to this method was inadequate sampling of cells in $58 \%$ of cases (defined as less than $50 \%$ cellularity in specimen). Western blotting has been used to demonstrate increased expression of epidermal growth factor receptors ErbB2 and ErbB3 in patients with keratoconjunctivitis sicca. ${ }^{24}$

Cells harvested from the cornea by impression cytology have been used for investigation of DNA polymorphisms using the polymerase chain reaction (fig 5). ${ }^{25}$ MUC 7 gene has been demonstrated in conjunctival cells obtained by impression cytology detecting elevated mRNA levels using semi-quantitative reverse transcriptase polymerase chain reaction (RT PCR). ${ }^{26}$ RT-PCR techniques have been used to show that defensin h-BD2 is preferentially expressed in moderate dry eye patients, and demonstrated that it can be induced in cultured conjunctival cells by exposing them to inflammatory cytokines. ${ }^{27}$

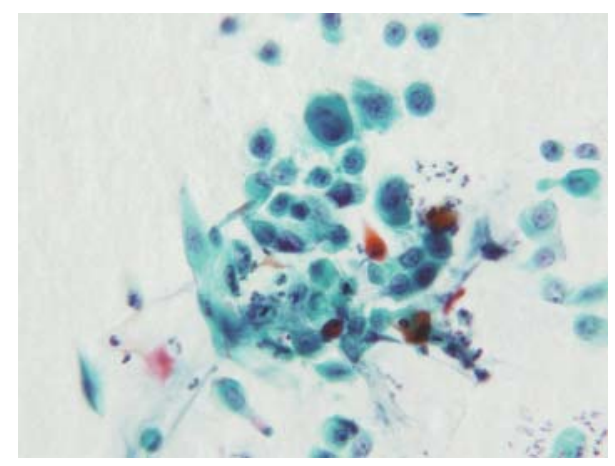

Figure 6 Impression cytology of the ocular surface showing dysplastic squamous cells with increased nucleus:cytoplasmic ratio, hyperchromatic nuclei, irregular nuclear membranes, and prominent nucleoli $(\times 250$ magnification, Papanicolaou stain). (Reproduced by courtesy of Dr Ushma Samaraweera, Department of Pathology, Prince of Wales Hospital, Sydney, Australia).
Pisella et al have used flow cytometry on conjunctival impression cytology specimens in dry eye and acne rosacea patients and found upregulation of HLA DR and ICAM-1 expression compared to control samples, supporting an inflammatory basis for their ocular surface disease. ${ }^{28}$ They also found a reduction in M-1 positive staining cells (goblet cell stain), and suggested inflammation may be responsible. Cytokines IL-6, IL-8, IL-10 have been found to be elevated in patients on chronic antiglaucoma medications using flow cytometry. ${ }^{29}$

Impression cytology has been used widely as a noninvasive method for conjunctival biopsy for suspected ocular surface squamous neoplasia (OSSN). ${ }^{30}$ Using biopore membrane for specimen collection an $80 \%$ correlation was found between impression cytology diagnosis and histopathology specimens obtained from incisional biopsy (fig 6). Keratinising malignancies offer the highest chance of false negatives because of paucity of cells in the specimen and should be kept in mind in such cases. Detailed cytomorphology of OSSN using impression cytology has been described. ${ }^{32}$ Mitomycin C (MMC) has gained acceptance for the treatment of OSSN especially in cases of recurrence or extensive disease where excision may jeopardise limbal stem cell function. McKelvie et al have followed patients after treatment with MMC for OSSN and, using impression cytology, demonstrated eradication of malignant cells, primarily by apoptosis, and a small amount of necrosis accompanied by inflammatory cells. ${ }^{33}$ Normal cells undergo cytoplasmic enlargement and vacuolisation, and nuclear enlargement, but maintained a normal nuclear to cytoplasmic ratio. These changes persisted for a variable time following treatment, but resolved eventually. Impression cytology has been studied in pigmented conjunctival lesions and predicted conjunctival melanocytic malignancy in $73 \%$ of cases studied..$^{34}$

Impression cytology has also been used to diagnose acanthomoeba keratitis in three patients by visualisation of cysts and trophozoites taken from the superficial cornea from patients with clinically suspicious infections. ${ }^{35}$

While there are numerous clinical and research applications of impression cytology, it has not yet become a routine diagnostic tool in most clinics because it is relatively cumbersome and time consuming for both the clinician and pathologist. However, the ability to obtain multiple samples of the ocular surface at one sitting with minimal discomfort to the patient makes it an ideal method of investigating ocular surface disorders when the diagnosis is not clinically obvious or when the clinical diagnosis needs to be substantiated and documented. It is also a handy research tool. We recommend that major ophthalmic centres should develop and introduce this technique into routine clinical practice. For this to be achieved a team approach including the ophthalmologist, pathologist, microbiologist, and the immunologist is essential.

\section{Authors' affiliations}

R Singh, A Joseph, T Umapathy, N L Tint, H S Dua, Division of Ophthalmology and Visual Sciences, Larry A Donoso Laboratory for Eye Research, University Hospital, Queen's Medical Centre, Nottingham NG7 2UH, UK

\section{REFERENCES}

1 Egbert PR, Lauber S, Maurice DM. A simple conjunctival biopsy. Am J Ophthalmol 1977;84:798-801.

2 Tseng SCG. Staging of conjunctival squamous metaplasia by impression cytology. Ophthalmology 1985;92:728-33.

3 Maskin SL, Bodé DD. Electron microscopy of impression-acquired conjunctival epithelial cells. Ophthalmology 1986;93:1518-23. 
4 Krenzer KL, Freddo TF. Cytokeratin expression in normal human bulbar conjunctiva obtained by impression cytology. Invest Ophthalmol Vis Sci 1997;38: 142-52.

5 Thiel MA, Bossart W, Bernauer W. Improved impression cytology techniques for the immunopathological diagnosis of superficial viral infections. Br J Ophthalmol 1997;81:984-8.

6 Vadrevu VLD, Fullard RJ. Enhancements to the conjunctival impression cytology technique and examples of applications in a clinico-biochemical study of dry eye. CLAO J 1994;20:59-63.

7 Gill GW, Frost JK, Miller KA. A new formula for a half-oxidised haematoxylin solution that neither over stains nor requires differentiation. Acta Cytol 1974;18:300-11.

8 Adams AD. The morphology of human conjunctival mucus. Arch Ophthalmol 1979;97:730-4.

9 Marner K. Snake-like appearance of nuclear chromatin in conjunctival epithelial cells from patients with keratoconjunctivitis sicca. Acta Ophthalmol (Copenh) 1980;58:849-53.

10 Nelson JD, Wright JC. Conjunctival goblet cell densities in ocular surface disease. Arch Ophthalmol 1984;102:1049-51

11 Wittpenn JR, Tseng SC, Sommer A. Detection of early xerophthalmia by impression cytology. Arch Ophthalmol 1996;104:237-9.

12 Nelson JD. Ocular surface impression using a cellulose acetate filter material. Arch Ophthalmol 1982;27:67-9.

13 Dogru M, Katakami C, Nakagawa N, et al. Impression cytology in atopic dermatitis. Ophthalmology 1998;105:1478-84.

14 Aragona P, Romeo G, Puzzolo D, et al. Impression cytology of the conjunctival epithelium in patients with vernal conjunctivitis. Eye 1996;10:82-5

15 Nelson DJ. Impression cytology. Cornea 1988;7:71-81.

16 Prabhasawat P, Tseng SCG. Impression cytology study of epithelial phenotype of ocular surface reconstructed by preserved human amniotic membrane. Arch Ophthalmol, 115:1360-7.

17 Tseng SH, Chen YT, Huang FC, et al. Seborrheic keratosis of the conjunctiva simulating a malignant melanoma. An immunocytochemical study with impression cytology. Ophthalmology 1999;106:1516-20.

18 Turacli E, Budak K, Kaur A, et al. The effects of long-term topical glaucoma medication on conjunctival impression cytology. Int Ophthalmol 1997;21:27-33.

19 Arici MK, Arici DS, Topalkara A, et al. Adverse effects of topical antiglaucoma drugs on the ocular surface. Clin Experiment Ophthalmol 2000;28:113-17.

20 Debbasch C, Pisella PJ, Rat $\mathrm{P}$, et al. Evaluation of free radical production by conjunctival impression cytology of patients treated with long-term antiglaucoma drugs or of contact lens wearers. J Fr Ophtalmol 2000;23:239-44.

21 Avunduk AM, Avunduk MC, Kapicioglu Z, et al. Mechanisms and comparison of anti-allergic efficacy of topical lodoxamide and cromolyn sodium treatment in vernal keratoconjunctivitis. Ophthalmology 2000;107:1333-7.

22 Dogru M, Katakmi C, Miyashita M, et al. Ocular surface changes after excimer laser phototherapeutic keratectomy. Ophthalmology 2000; 107:11 44-52.

23 Shimazaki J, Yang H, Tsubota K. Amniotic membrane transplantation for ocular surface reconstruction in patients with chemical and thermal burns. Ophthalmology 1997; 104:2068-76.

24 Liu Z, Carvajal M, Carothers CA, et al. Increased expression of the type 1 growth factor receptor family in the conjunctival epithelium of patients with keratoconjunctivitis sicca. Am J Ophthalmol 2000;129:472-80.

25 Williams KA, Brereton HM, Aggarwal R, et al. Use of DNA polymorphisms and the polymerase chain reaction to examine the survival of a human limbal stem cell allograft. Am J Ophthalmol 1995; 120:342-50.

26 Corrales RM, Calonge M, Herreras JM, et al. Human epithelium from conjunctival impression cytology expresses MUC7 mucin gene. Cornea 2003;22:665-71.

27 Narayanan S, Miller W, McDermott A. Expression of human $\beta$-defensins in conjunctival epithelium: relevance to dry eye disease. Invest Ophthalmol Vis Sci 2003:44:3795-801.

28 Pisella P, Brignole F, Debbasch C, et al. Flow cyłometric analysis of conjunctival epithelium in ocular rosacea and keratoconjunctivitis sicca. Ophthalmology 2000;107:1841-9.

29 Baudouin $\mathrm{C}$, Harnard $\mathrm{P}$, Liang $\mathrm{H}$, et al. Conjunctival epithelial cell expression of interleukins and inflammatory markers in glaucoma patients treated over the long term. Ophthalmology, 20004, 111:2186-92.

30 Tole D, McKelvie, Daniell M. Reliability of impression cytology for the diagnosis of ocular surface squamous neoplasia employing the Biopre membrane. Br J Ophthalmol 2001;85:154-8.

31 Nolan GR, Hirst LW, Wright RG, et al. Application of impression vytology to the diagnosis of conjunctival neoplasm. Diagn Cytopathol 1994;11:246-9.

32 Nolan GR, Hirst LW, Bancroft NJ. The cytomorphology of ocular surface squamous neoplasia using impression cytology. Cancer 2001;93:60-7.

33 McKelvie PA, Daniell M. Impression cytology following mitomycin C therapy for ocular surface neoplasia. Br J Ophthalmol 2000;85:1115-19.

34 Paridaens ADA, McCatney ACE, Curlin OM, et al. Impression cytology of conjunctival melanosis. Br J Ophthalmol 1992;76:198-201.

35 Sawada Y, Yuan C, Huang AJ. Impression cytology in the diagnosis of acanthamoeba keratitis with surface involvement. Am J Ophthalmol 2004; 137:328-8. 